\title{
Synthesis and Optical Characterization of Mixed Ligands Beryllium Complexes for Display Device Applications
}

\author{
Vandna Nishal, Devender Singh, Raman Kumar Saini, Vijeta Tanwar, Shri Bhagwan, \\ Sonika Kadyan, Ishwar Singh, and Pratap Singh Kadyan \\ Department of Chemistry, Maharshi Dayanand University, Rohtak, Haryana 124001, India \\ Correspondence should be addressed to Devender Singh; devjakhar@gmail.com \\ and Pratap Singh Kadyan; pskadyan@rediffmail.com
}

Received 7 June 2015; Revised 8 September 2015; Accepted 28 September 2015

Academic Editor: Marek Samoc

Copyright (c) 2015 Vandna Nishal et al. This is an open access article distributed under the Creative Commons Attribution License, which permits unrestricted use, distribution, and reproduction in any medium, provided the original work is properly cited.

Synthesis and photoluminescent behaviour of mixed ligand based beryllium complexes with 2-(2-hydroxyphenyl)benzoxazole (HPB) and 5-chloro-8-hydroxyquinoline (Clq) or 5,7-dichloro-8-hydroxyquinoline $\left(\mathrm{Cl}_{2} \mathrm{q}\right)$ or 2-methyl-8-hydroxyquinoline (Meq) or 8-hydroxyquinoline (q) are reported in this work. These complexes, that is, [BeHPB(Clq)], $\left[\mathrm{BeHPB}\left(\mathrm{Cl}_{2} \mathrm{q}\right)\right]$, $[\mathrm{BeHPB}(\mathrm{Meq})]$, and $[\mathrm{BeHPB}(\mathrm{q})]$, were prepared and their structures were confirmed by elemental analysis, Fourier transform infrared spectroscopy, nuclear magnetic resonance spectroscopy, and thermal analysis. The beryllium complexes exhibited good thermal stability up to $\sim 300^{\circ} \mathrm{C}$ temperature. The photophysical properties of beryllium complexes were studied using ultraviolet-visible absorption and photoluminescence emission spectroscopy. The complexes showed absorption peaks due to $\pi-\pi^{*}$ and $n-\pi^{*}$ electronic transitions. The complexes emitted greenish blue light with peak wavelength at $496 \mathrm{~nm}, 510 \mathrm{~nm}, 490 \mathrm{~nm}$, and $505 \mathrm{~nm}$, respectively, consisting of high intensity. Color tuning was observed with changing the substituents in quinoline ring ligand in metal complexes. The emitted light had Commission Internationale d'Eclairage color coordinates values at $x=0.15$ and $y=0.43$ for [BeHPB $(\mathrm{Clq})], x=0.21$ and $y=0.56$ for $\left[\mathrm{BeHPB}\left(\mathrm{Cl}_{2} \mathrm{q}\right)\right], x=0.14$ and $y=0.38$ for $[\mathrm{BeHPB}(\mathrm{Meq})], x=0.17$ and $y=0.41$ for $[\mathrm{BeHPB}(\mathrm{q})]$. Theoretical calculations using DFT/B3LYP/6-31G(d,p) method were performed to reveal the three-dimensional geometries and the frontier molecular orbital energy levels of these synthesized metal complexes.

\section{Introduction}

Small molecular metal complexes $[1,2]$ and polymeric materials $[3,4]$ have been extensively used for the fabrication of organic light emitting devices (OLEDs) which have been widely exploited due to their potential applications in future generation flat panel displays and solid state light sources $[5,6]$. OLEDs offer several advantages over inorganic counterparts such as low cost, self-emission, broad tunability, and high luminous efficiency $[7,8]$. For the commercial application of active matrix full color displays with OLEDs much effort has been directed towards improving their characteristics especially color tuning $[9,10]$. There is a wide selection of emission colors in electroluminescent (EL) displays attainable through structural design of organic materials. The photophysical properties such as light emission, charge transport, and degradation at high temperature have been modified by organic ligands used in metal complexes [11]. Numerous derivatives of 8-hydroxyquinolines have been synthesized and used for metal complex formation $[12,13]$.

For color tuning tris(8-hydroxyquinolinato)aluminium $\left(\mathrm{Alq}_{3}\right)[1]$ and bis(10-hydroxybenzo[ $\left.h\right]$ quinolinato)beryllium $\left(\mathrm{Bebq}_{2}\right)[14]$ which emit green light are considered as the most excellent emitting materials for organic EL devices. The emissions of $\mathrm{Alq}_{3}$ and $\mathrm{Bebq}_{2}$ originate from the electronic $\pi-\pi^{*}$ transitions within q or bq ligands. The two molecules are typical ligand-centered luminescent complexes. Beryllium complexes with N,O ligands have also been developed as efficient electron transport host materials for electroluminescent devices $[15,16]$. Beryllium(II) complexes of aromatic N,Ochelate ligands, as blue EL materials, have been reported by Tong et al. [17] who have shown that the absorption and luminescent properties of these complexes are ligand based. The work has demonstrated that the ligand-tuning approach 
<smiles>[R]c1ccc2c([R])cc([R3])c(O)c2n1</smiles>

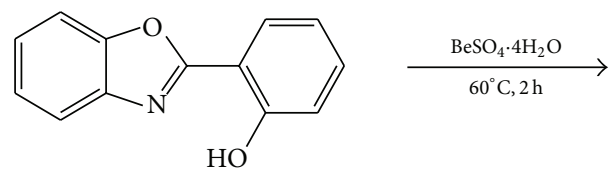

$$
\begin{aligned}
& \text { For } \operatorname{BeHPB}(\mathrm{Clq}): \mathrm{R}_{1}=\mathrm{H}, \mathrm{R}_{2}=\mathrm{Cl}, \mathrm{R}_{3}=\mathrm{H} \\
& \text { For } \operatorname{BeHPB}\left(\mathrm{Cl}_{2} \mathrm{q}\right): \mathrm{R}_{1}=\mathrm{H}, \mathrm{R}_{2}=\mathrm{Cl}, \mathrm{R}_{3}=\mathrm{Cl} \\
& \text { For } \operatorname{BeHPB}(\mathrm{Meq}): \mathrm{R}_{1}=\mathrm{Me}, \mathrm{R}_{2}=\mathrm{H}, \mathrm{R}_{3}=\mathrm{H} \\
& \text { For } \operatorname{BeHPB}(\mathrm{q}): \mathrm{R}_{1}=\mathrm{H}, \mathrm{R}_{2}=\mathrm{H}, \mathrm{R}_{3}=\mathrm{H}
\end{aligned}
$$<smiles></smiles>

FIGURE 1: Synthetic route of the beryllium complexes.

might be useful for the preparation of potential luminescent metal-organic materials with different emitting colors.

Here we have tried quinolate and N,O donor ligand for tuning the color of the emissive metal chelates and therefore synthesized mixed ligand beryllium complexes with 2-(2hydroxyphenyl)benzoxazole and 8-hydroxyquinoline as well as its substituted derivatives. The photophysical properties of these materials have also been investigated.

\section{Experimental Details}

2.1. Synthesis of Metal Complexes. All the chemicals used to synthesize metal complexes were of analytical grade and purchased from Fluka. Solvents were of high purity and used as supplied.

Beryllium complexes were prepared by reacting two ligands, first as 2-(2-hydroxyphenyl)benzoxazole (HPB) and second as 5-chloro-8-hydroxyquinoline (Clq)/5,7-dichloro8-hydroxyquinoline $\left(\mathrm{Cl}_{2} \mathrm{q}\right) / 2$-methyl-8-hydroxyquinoline (Meq)/8-hydroxyquinoline (q) separately with beryllium sulphate (ligands and metal) at 1:1:1 molar ratio in ethanol. A solution of HPB $0.5 \mathrm{~g}(1 \mathrm{mmol})$ was prepared in $20 \mathrm{~mL}$ pure ethanol and stirred on a magnetic stirrer at $60^{\circ} \mathrm{C}$ for $30 \mathrm{~min}$ and then a solution of Clq $0.36 \mathrm{~g}(1 \mathrm{mmol}) / \mathrm{Cl}_{2} \mathrm{q} 0.43 \mathrm{~g}$ $(1 \mathrm{mmol}) / \mathrm{Meq} 0.32 \mathrm{~g}(1 \mathrm{mmol}) / \mathrm{q} 0.29 \mathrm{~g}(1 \mathrm{mmol})$ in $20 \mathrm{~mL}$ of pure ethanol was added to the reaction mixture. The reaction mixture was stirred at $60^{\circ} \mathrm{C}$ for $2 \mathrm{~h}$; then a solution of beryllium sulphate $(1 \mathrm{mmol})$ in $5 \mathrm{~mL}$ of deionized water was added dropwise. The yellowish precipitate of the complexes was formed, filtered, and dried at $100^{\circ} \mathrm{C}$. The synthetic scheme is shown in Figure 1.

2.2. Instrumentation. The elemental contents of carbon, hydrogen, and nitrogen were detected by Elemental Analyzer PerkinElmer $2400 \mathrm{CHN}$ using combustion technique. PerkinElmer 2000 FTIR spectrometer using dry $\mathrm{KBr}$ was used to run IR spectral data in the range $4000-400 \mathrm{~cm}^{-1}$. ${ }^{1} \mathrm{H}$ NMR analysis was performed by Bruker Avance 300 Proton NMR Spectrometer in $\mathrm{CDCl}_{3}$. Thermal gravimetric analysis
(TGA) and differential thermal analysis (DTA) were carried out using Mettler Toledo TGA/SDTA851e instrument. Absorbances of these complexes (in methanol) and photoluminescence spectra (in solid and thin film) were recorded using spectrophotometer Horiba Jobin YVON Fluorolog Model FL-3-11 equipped with $450 \mathrm{~W}$ Xenon lamp as the excitation source. Optimized three-dimensional stable structures of metal complexes and their selected frontier molecular orbitals were obtained by density functional theory using Gaussian 03 package.

\subsection{Structural Characterization of Synthesized Complexes}

2.3.1. (2-(2-Hydroxyphenyl)benzoxazolato)(5-chloro-8-hydroxyquinolinato)beryllium(II). Yield: 65.2\%; Anal. Calc. $\left(\mathrm{C}_{22} \mathrm{H}_{13} \mathrm{~N}_{2} \mathrm{O}_{3} \mathrm{BeCl}\right.$ ) (found: $\mathrm{C}, 66.32 ; \mathrm{H}, 3.29 ; \mathrm{N}, 7.06$; calc.: $\mathrm{C}$, 66.41; H, 3.27; N, 7.04\%); IR(KBr): $v\left(\mathrm{~cm}^{-1}\right) 2990,1662,1574$, $1606,1256,600-800 ;{ }^{1} \mathrm{H} \mathrm{NMR}\left(\mathrm{CDCl}_{3}\right): \delta(\mathrm{ppm}) 6.77(\mathrm{~m} \mathrm{1H})$, $7.10(\mathrm{~m} 1 \mathrm{H}), 7.34-7.92(\mathrm{~m} 8 \mathrm{H}), 8.4(\mathrm{~m} 1 \mathrm{H}), 8.72(\mathrm{~m} 1 \mathrm{H})$.

2.3.2. (2-(2-Hydroxyphenyl)benzoxazolato)(5,7-dichloro-8hydroxyquinolinato)beryllium(II). Yield: 63.8\%; Anal. Calc. $\left(\mathrm{C}_{22} \mathrm{H}_{12} \mathrm{~N}_{2} \mathrm{O}_{3} \mathrm{BeCl}_{2}\right.$ ) (found: $\mathrm{C}, 61.06 ; \mathrm{H}, 2.79 ; \mathrm{N}, 6.51$; calc.: C, 61.11; H, 2.77; N, 6.48\%); IR(KBr): $v\left(\mathrm{~cm}^{-1}\right) 2904,1661$, $1608,1579,1251,600-800 ;{ }^{1} \mathrm{H} \mathrm{NMR}\left(\mathrm{CDCl}_{3}\right): \delta(\mathrm{ppm}) 6.91(\mathrm{~m}$ $1 \mathrm{H}), 7.09(\mathrm{~m} \mathrm{lH}), 7.35-7.91(\mathrm{~m} 8 \mathrm{H}), 8.35(\mathrm{~m} \mathrm{lH}), 8.82(\mathrm{~m} \mathrm{lH})$.

2.3.3. (2-(2-Hydroxyphenyl)benzoxazolato)(2-methyl-8-hydroxyquinolinato)beryllium(II). Yield: 66.8\%; Anal. Calc. $\left(\mathrm{C}_{23} \mathrm{H}_{16} \mathrm{~N}_{2} \mathrm{O}_{3} \mathrm{Be}\right)$ (found: $\mathrm{C}, 73.16 ; \mathrm{H}, 4.26 ; \mathrm{N}, 7.45$; calc.: $\mathrm{C}$, 73.20; H, 4.24; N, 7.42\%); IR(KBr): $v\left(\mathrm{~cm}^{-1}\right)$ 2905, 1661, 1608, $1579,1251,600-800 ;{ }^{1} \mathrm{H}$ NMR $\left(\mathrm{CDCl}_{3}\right): \delta(\mathrm{ppm}) 2.50$ (s $\left.3 \mathrm{H}\right)$, $6.95(\mathrm{~m} \mathrm{1H}), 7.10-7.92(\mathrm{~m} \mathrm{11H}), 8.04(\mathrm{~m} 1 \mathrm{H})$.

2.3.4. (2-(2-Hydroxyphenyl)benzoxazolato)(8-hydroxyquinolinato)beryllium(II). Yield: 62.8\%; Anal. Calc. $\left(\mathrm{C}_{22} \mathrm{H}_{14} \mathrm{~N}_{2} \mathrm{O}_{3} \mathrm{Be}\right.$ ) (found: $\mathrm{C}, 72.75 ; \mathrm{H}, 3.87 ; \mathrm{N}, 7.74$; calc.: $\mathrm{C}$, 72.72; H, 3.85; N, 7.71\%); IR(KBr): $v\left(\mathrm{~cm}^{-1}\right) 2993,1662,1607$, $1570,1250,600-800 ;{ }^{1} \mathrm{H} \mathrm{NMR}\left(\mathrm{CDCl}_{3}\right): \delta(\mathrm{ppm}) 6.93(\mathrm{~m} 1 \mathrm{H})$, $7.15(\mathrm{~m} 2 \mathrm{H}), 7.26-7.92(\mathrm{~m} \mathrm{9H}), 8.06(\mathrm{~m} 1 \mathrm{H})$. 
TABLE 1: Photophysical properties of beryllium complexes.

\begin{tabular}{|c|c|c|c|c|c|c|}
\hline Compound & $\begin{array}{c}\text { Absorption } \\
(\mathrm{nm})\end{array}$ & $\begin{array}{c}\text { Emission } \\
\lambda_{\max }(\mathrm{nm}) \\
\end{array}$ & $\begin{array}{c}\text { Optical band gap } \\
(\mathrm{eV})\end{array}$ & $\begin{array}{l}\text { Thin film } \\
\text { PL (nm) }\end{array}$ & Emitted light & Color coordinates \\
\hline BeHPB(Clq) & 287,338 & 493 & 3.02 & 497 & Greenish blue & $x=0.15, y=0.43$ \\
\hline $\mathrm{BeHPB}\left(\mathrm{Cl}_{2} \mathrm{q}\right)$ & 278,378 & 496 & 2.93 & 499 & Green & $x=0.21, y=0.56$ \\
\hline $\mathrm{BeHPB}(\mathrm{Meq})$ & 246,365 & 486 & 3.07 & 487 & Greenish blue & $x=0.14, y=0.38$ \\
\hline $\operatorname{BeHPB}(q)$ & 282,332 & 507 & 2.98 & 511 & Greenish blue & $x=0.17, y=0.41$ \\
\hline
\end{tabular}

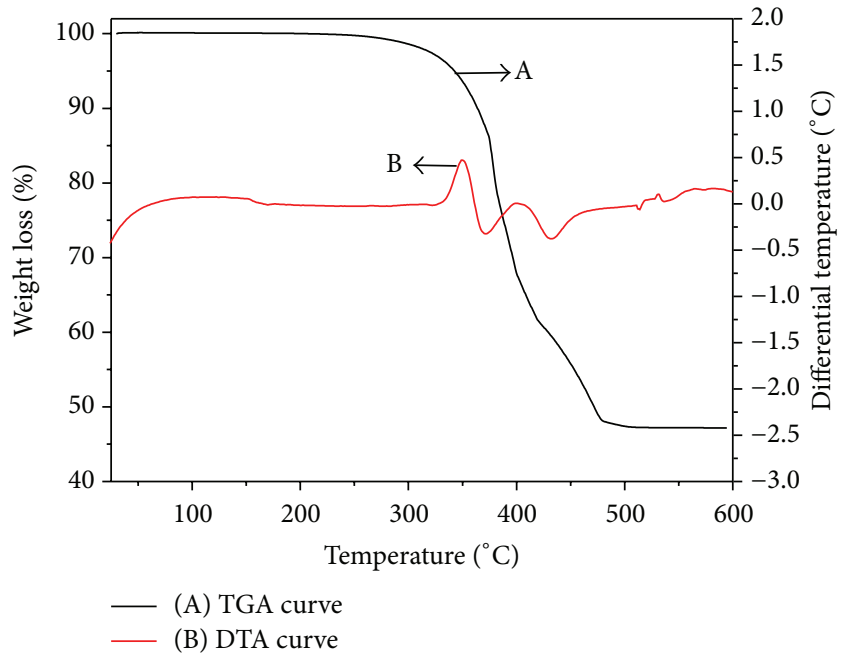

Figure 2: Curve (A): TGA, and curve (B): DTA plots of $[\mathrm{BeHPB}(\mathrm{Clq})]$ complex.

\section{Results and Discussion}

3.1. Thermal Characterization. The thermogravimetric analysis (TGA) and the differential thermal analysis (DTA) of beryllium complexes were carried out in nitrogen atmosphere with a heating rate of $10^{\circ} \mathrm{C} / \mathrm{min}$ in temperature range of $0-500^{\circ} \mathrm{C}$. The metal complexes exhibited high thermal stability and analogous thermal pattern of weight loss was observed at decomposition temperature for all complexes. The onset temperature of weight loss was $300^{\circ} \mathrm{C}$, and temperature for nearly $10 \%$ weight loss was $350^{\circ} \mathrm{C}$ as shown in TGA plot of $[\mathrm{BeHPB}(\mathrm{Clq})]$ in Figure 2. Above $400^{\circ} \mathrm{C}$ temperature the complex lost all of its weight continuously and decomposed completely. TGA data of the complex shows that this complex exhibited excellent thermal stability. Curve B of Figure 2 corresponds to DTA of $[\mathrm{BeHPB}(\mathrm{Clq})]$ in nitrogen atmosphere.

3.2. Optical Absorption and Photoluminescent Spectra. The photophysical properties as absorption and emission characteristics of beryllium complexes were studied using spectroscopy techniques. Figure 3 shows the room temperature UV-visible absorption spectra of beryllium complexes in methanol. The beryllium complexes $[\mathrm{BeHPB}(\mathrm{Clq})]$, $\left[\mathrm{BeHPB}\left(\mathrm{Cl}_{2} \mathrm{q}\right)\right],[\mathrm{BeHPB}(\mathrm{Meq})]$, and $[\operatorname{BeHPB}(\mathrm{q})]$ exhibited similar absorption bands from 200 to $400 \mathrm{~nm}$ with maximum absorption at $287,278,246$, and $282 \mathrm{~nm}$ due to $\pi-\pi^{*}$ transition

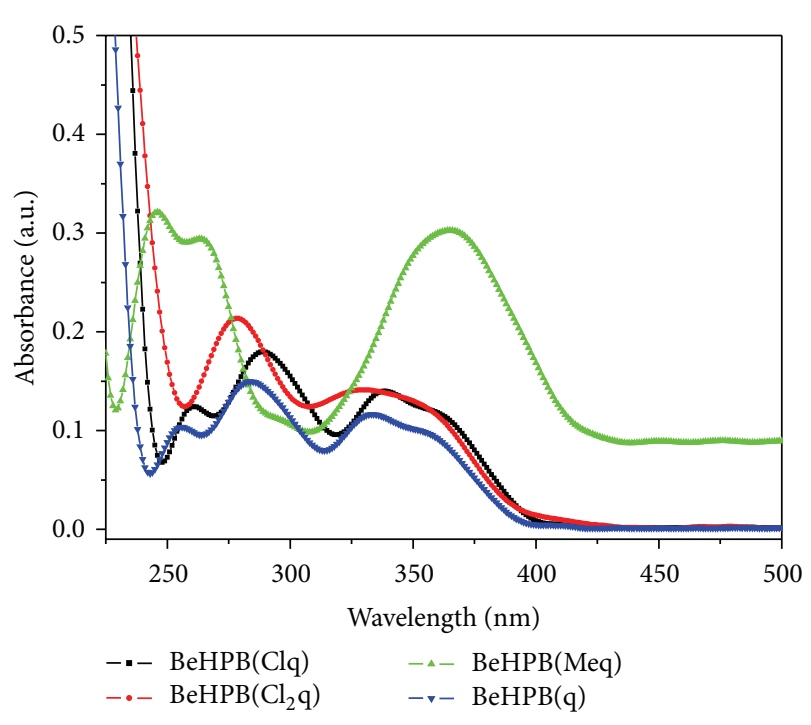

FIGURE 3: UV-visible absorption spectra of beryllium complexes at $10^{-4} \mathrm{M}$ concentration in methanol.

and at $338,378,365$, and $332 \mathrm{~nm}$ due to $n-\pi^{*}$ electronic transitions, respectively. The molar absorptivity of beryllium complexes [BeHPB $(\mathrm{Clq})],\left[\mathrm{BeHPB}\left(\mathrm{Cl}_{2} \mathrm{q}\right)\right]$, [BeHPB(Meq)], and $[\mathrm{BeHPB}(\mathrm{q})]$ was $1398,1412,2191$, and $1175 \mathrm{~cm}^{-1}$, respectively, at maximum absorption wavelength.

The optical band gap was calculated from absorption spectra; Figure 4 shows band gap graph for [BeHPB $(\mathrm{Clq})]$ and $\left[\mathrm{BeHPB}\left(\mathrm{Cl}_{2} \mathrm{q}\right)\right]$ with values 3.03 and $2.98(\mathrm{eV})$, respectively.

Upon excitation at absorption wavelengths the materials $[\mathrm{BeHPB}(\mathrm{Clq})],\left[\mathrm{BeHPB}\left(\mathrm{Cl}_{2} \mathrm{q}\right)\right],[\mathrm{BeHPB}(\mathrm{Meq})]$, and $[\mathrm{BeHPB}(\mathrm{q})]$ fluoresced at 493, 496, 486, and $507 \mathrm{~nm}$, respectively, in the visible spectra as shown in Figure 5. The photoluminescence intensities of beryllium complexes were found in order as $\left[\mathrm{BeHPB}\left(\mathrm{Cl}_{2} \mathrm{q}\right)\right]<[\mathrm{BeHPB}(\mathrm{q})]<[\mathrm{BeHPB}(\mathrm{Clq})]<$ $[\mathrm{BeHPB}(\mathrm{Meq})]$ as observed from the graph in Figure 5 . The complexes emitted bright greenish blue colored light. The values of electronic transitions and emission wavelengths are presented in Table 1. Beryllium complex with 2-(2hydroxyphenyl)benzoxazole ligand emits light at $440 \mathrm{~nm}$ [17] and with 8-hydroxyquinoline ligand emits light at $520 \mathrm{~nm}$ [18]. Beryllium metal complexes emit at lower wavelength than Zinc metal complexes as Be is lighter metal than $\mathrm{Zn}$. Beryllium complexes emit in greenish blue region while zinc complexes with similar ligands emit in blue-green region. The electroluminescent devices based on $\mathrm{Be}(\mathrm{II})$ complexes have 


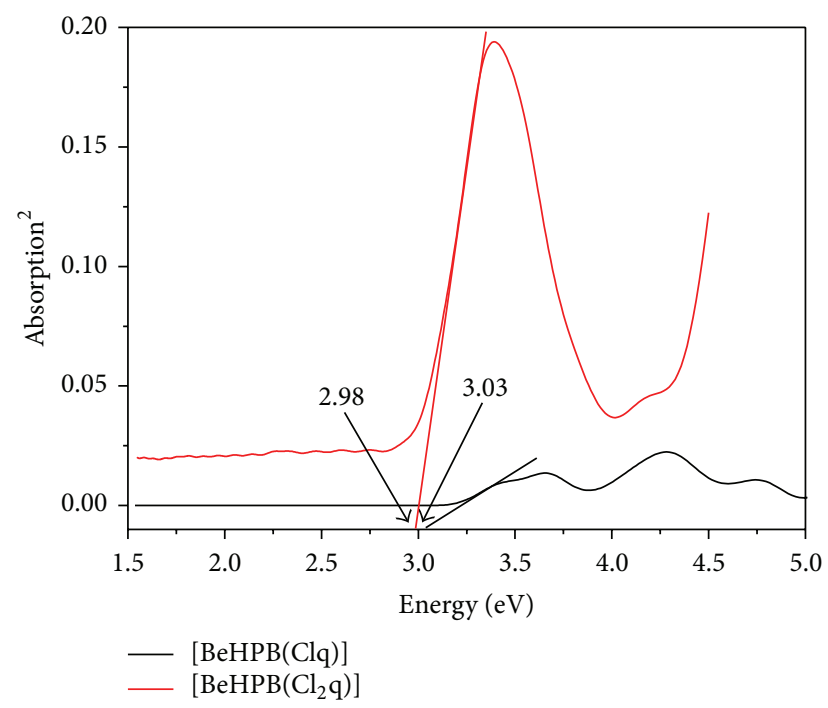

FIGURE 4: Energy versus absorption ${ }^{2}$ plot of beryllium complexes.

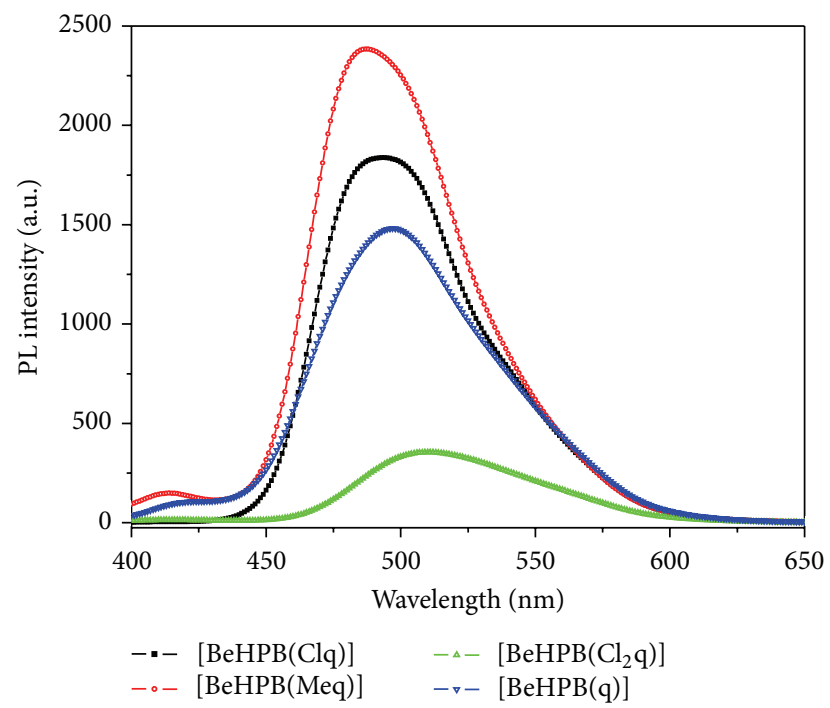

FIGURE 5: Photoluminescence spectra of beryllium(II) complexes in solid state.

brighter luminance than devices fabricated with other similar metal complexes [14]. There was shift in emission wavelength on attaching electron withdrawing groups on phenol ring as in quinolate complexes $[19,20]$. Blue shift in emission wavelength of $[\mathrm{BeHPB}(\mathrm{Clq})]$ and $[\mathrm{BeHPB}(\mathrm{Meq})]$ was observed as compared to that of $[\mathrm{BeHPB}(\mathrm{q})]$. This was due to attaching of electron withdrawing groups, that is, chloro at phenolic ring, and electron donating groups, that is, methyl at pyridyl ring. The highest occupied molecular orbitals (HOMOs) and lowest unoccupied molecular orbitals (LUMOs) in 8-hydroxyquinoline were present on phenoxide ring and pyridyl ring, respectively [21]. The central metal atom provided stability to the ligands and modification of ligands lead to change in emission wavelength as well as energy. The thin film PL of the beryllium complexes was recorded at absorption wavelength by deposition of a thin film of thickness $200 \AA$ on the glass substrate by thermal deposition technique.

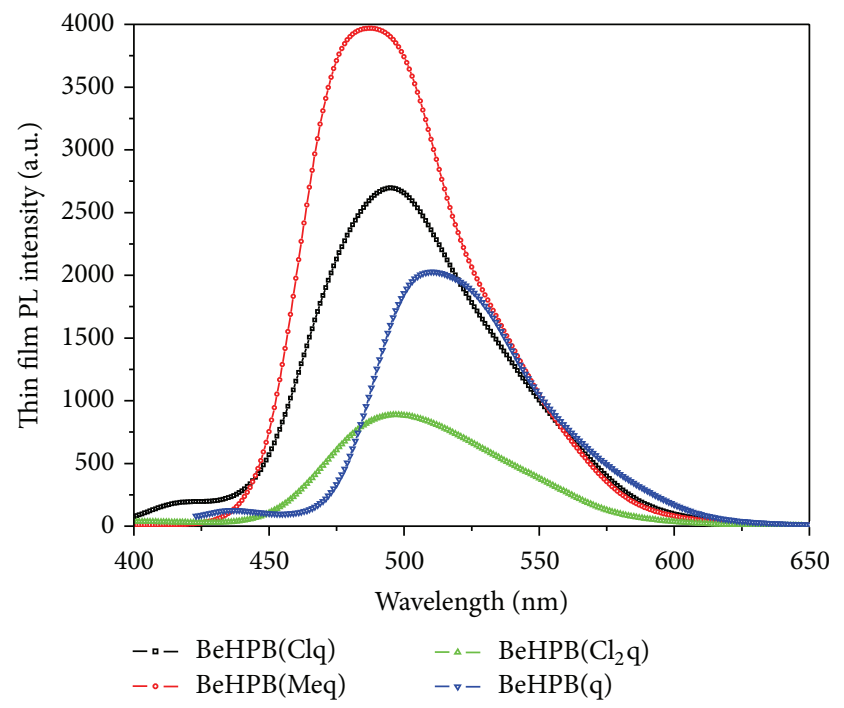

FIgURE 6: Photoluminescence spectra of beryllium(II) complexes in thin film form on glass substrate.

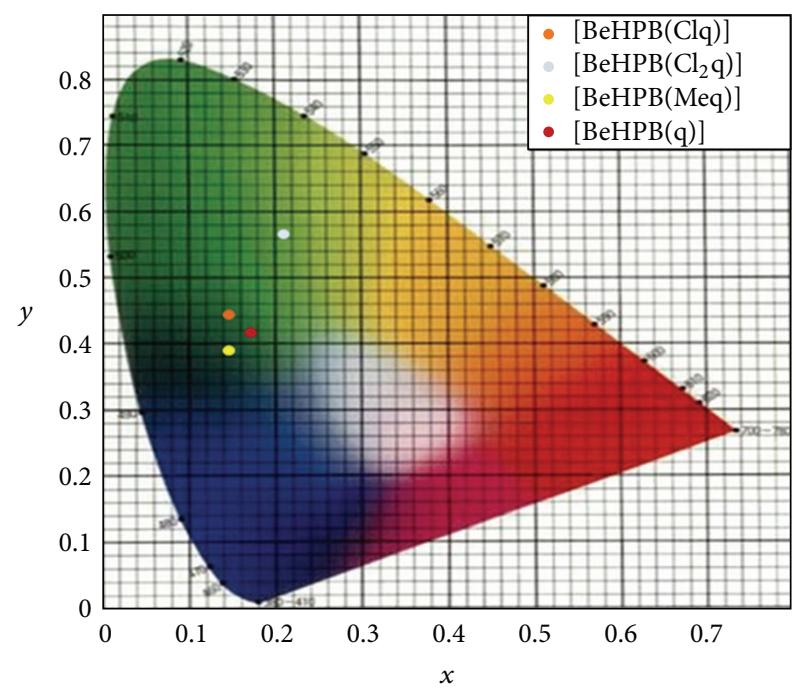

Figure 7: CIE chromaticity diagram.

The photoluminescent spectra of beryllium metal complexes in thin film form have been shown in Figure 6 and the peak values are mentioned in Table 1 . The PL peaks values were slightly red shifted and having high intensity as compared to that in solid powdered form. The synthesized complexes exhibited film forming behaviour and here it is also observed that ligand alteration and improvement approach can be useful for synthesis of desired potential fluorescent materials especially beryllium complexes, with different emitting colors and required energy gap between HOMOs and LUMOs.

The Commission Internationale d'Eclairage (CIE) 1931 chromaticity color coordinates for emitted color of PL in solid powdered form were $x=0.15$ and $y=0.43$ for [BeHPB(Clq)], $x=0.21$ and $y=0.56$ for $\left[\mathrm{BeHPB}\left(\mathrm{Cl}_{2} \mathrm{q}\right)\right]$, $x=0.14$ and $y=0.38$ for $[\mathrm{BeHPB}(\mathrm{Meq})]$, and $x=0.17$ and $y=0.41$ for $[\operatorname{BeHPB}(q)]$, also represented in Figure 7. 


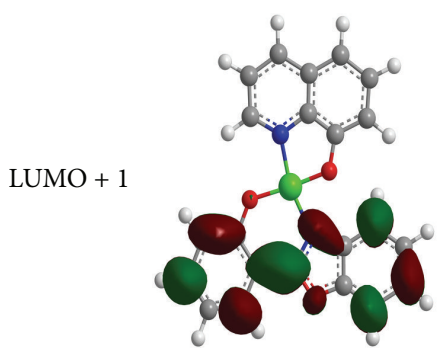

$(-1.61 \mathrm{eV})$

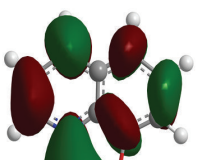

LUMO

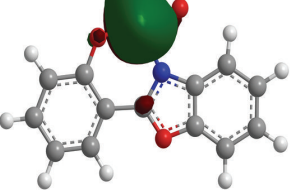

$(-2.02 \mathrm{eV})$

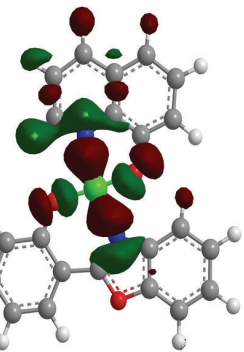

$(-5.09 \mathrm{eV})$

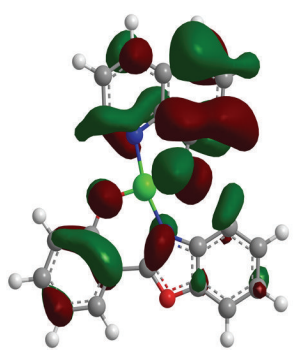

$(-5.21 \mathrm{eV})$

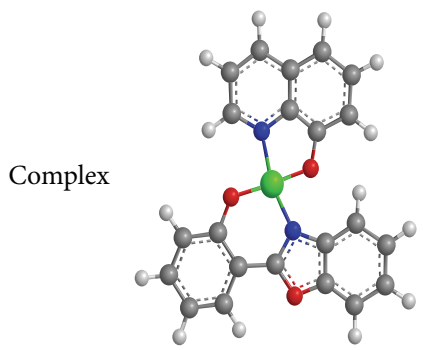

$[\operatorname{BeHPB}(q)$

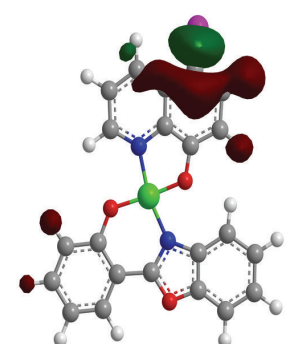

$(-1.73 \mathrm{eV})$

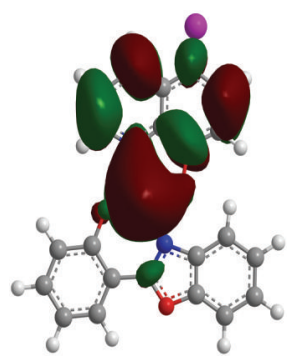

$(-2.19 \mathrm{eV})$

$(-5.18 \mathrm{eV})$
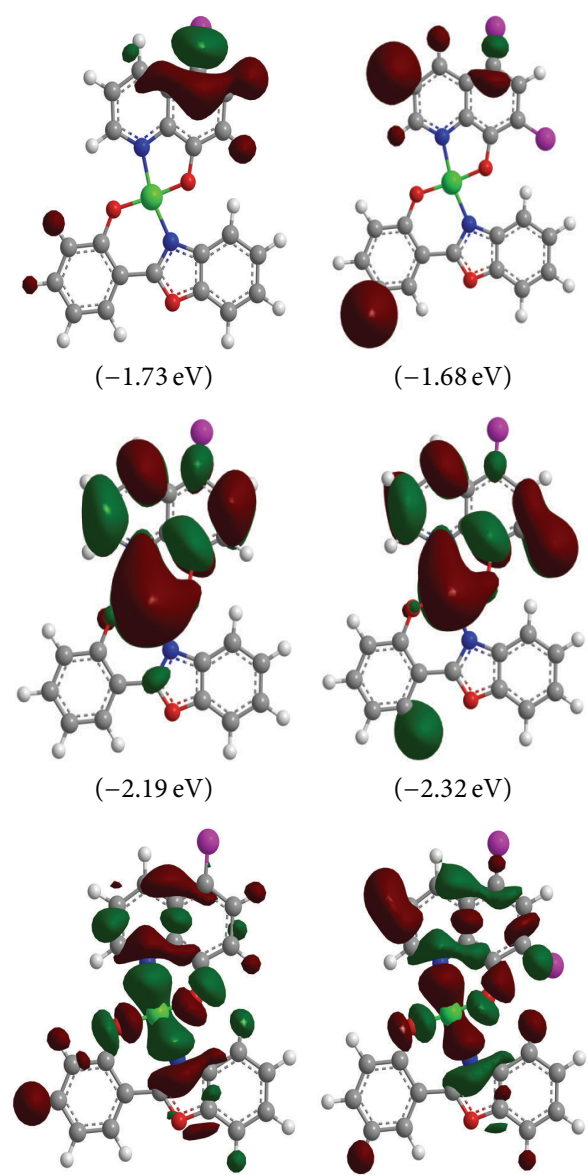

$(-1.68 \mathrm{eV})$

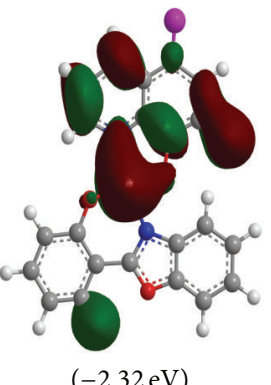

$(-2.32 \mathrm{eV})$

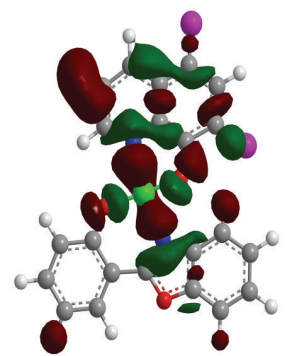

$(-4.96 \mathrm{eV})$

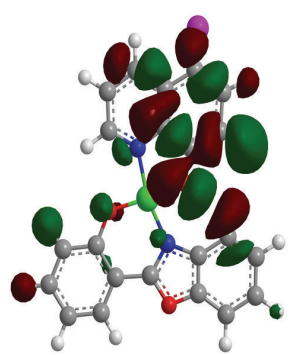

$(-5.35 \mathrm{eV})$

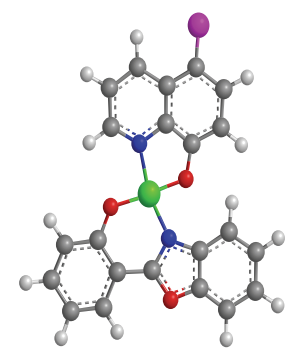

[BeHPB(Clq)]

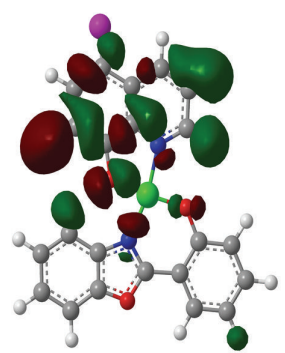

$(-5.12 \mathrm{eV})$

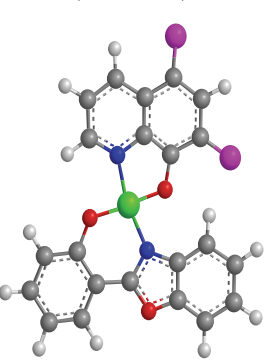

$\left[\mathrm{BeHPB}\left(\mathrm{Cl}_{2} \mathrm{q}\right)\right]$

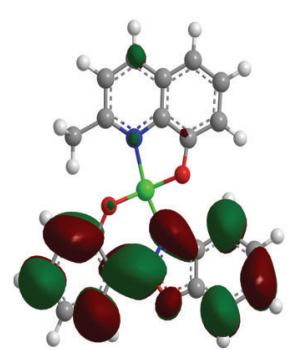

$(-1.65 \mathrm{eV})$
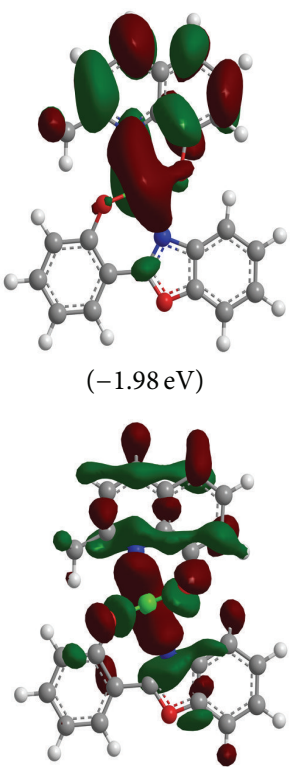

$(-5.16 \mathrm{eV})$

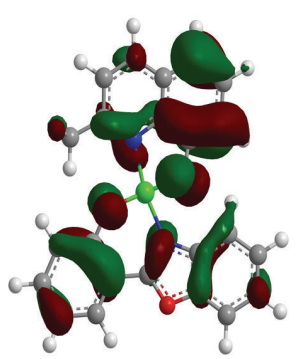

$(-5.29 \mathrm{eV})$

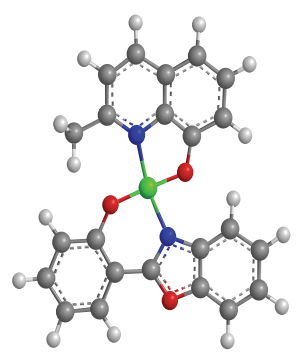

[BeHPB(Meq)]

FIGURE 8: Optimized 3D molecular geometry, molecular orbital surfaces $\left(0.05 \mathrm{e} \mathrm{au}^{-3}\right)$, and energies (in parenthesis, eV) of the selected frontier molecular orbitals of beryllium(II) complexes. 
3.3. Density Functional Theory (DFT) Calculations. The minimal energy three-dimensional geometries and frontier molecular orbitals of prepared beryllium(II) complexes were computed with DFT/B3LYP/6-31G(d,p) method [22]. The FMOs are principally dominated by the orbitals originating from those of the ligand in the complex and contribution from the beryllium(II) ion appears to be small.

The optimized 3D structures and selected FMOs such as HOMO - 1, HOMO, LUMO, and LUMO + 1 are shown in Figure 8 . The electron withdrawing nature of chloro $(-\mathrm{Cl})$ substituents fixed to the 5-position and 7-position of ligand and electron donating nature of methyl $\left(-\mathrm{CH}_{3}\right)$ substituents fixed to 2-position of ligand are used to tune the energy of HOMO and LUMO levels to achieve blue shift emission as optical transition responsible for photoluminescence may be attributed due to the transition between HOMO and LUMO [23]. The numerical values of all selected FMOs in eV are also shown in Figure 8. The findings of optical band gap were supported by the DFT calculation of the FMOs and the HOMO-LUMO gap at DFT/B3LYP/6-31G(d,p) studies.

\section{Conclusions}

Beryllium complexes were synthesized and characterized by elemental analysis, ${ }^{1} \mathrm{HNMR}$, and FTIR techniques. The metal complexes had high thermal and chemical stability which were confirmed by TGA and DTA. The photophysical properties were investigated by absorption and emission spectroscopy. The emission maxima of the complexes were found in the greenish blue region having high intensity. The emission wavelength was $493 \mathrm{~nm}$ for [BeHPB(Clq)], $496 \mathrm{~nm}$ for [BeHPB( $\left.\left(\mathrm{Cl}_{2} \mathrm{q}\right)\right], 486 \mathrm{~nm}$ for [BeHPB(Meq)], and $507 \mathrm{~nm}$ for $[\mathrm{BeHPB}(\mathrm{q})]$ material. Ligand tuning can be useful for desirable light emission. The photoluminescent characterization confirmed the better luminescence properties of these complexes that could be efficiently used as emissive materials for display device applications.

\section{Conflict of Interests}

The authors declare that there is no conflict of interests regarding the publication of this work.

\section{Authors' Contribution}

Vandna Nishal and Devender Singh contributed equally to this work.

\section{Acknowledgments}

The authors gratefully recognize the financial support from the University Grant Commission (UGC) and Council of Scientific and Industrial Research (CSIR), New Delhi, India.

\section{References}

[1] C. W. Tang and S. A. VanSlyke, "Organic electroluminescent diodes," Applied Physics Letters, vol. 51, no. 12, pp. 913-915, 1987.
[2] L. M. Leung, W. Y. Lo, S. K. So, K. M. Lee, and W. K. Choi, "A high-efficiency blue emitter for small molecule-based organic light-emitting diode," Journal of the American Chemical Society, vol. 122, no. 23, pp. 5640-5641, 2000.

[3] H. L. Wang, A. G. MacDiarmid, Y. Z. Wang, D. D. Gebler, and A. J. Epstein, "Application of polyaniline (emeraldine base, EB) in polymer light-emitting devices," Synthetic Metals, vol. 78, no. 1, pp. 33-37, 1996.

[4] A. Liedtke, M. O’Neill, A. Wertmöller, S. P. Kitney, and S. M. Kelly, "White-light OLEDs using liquid crystal polymer networks," Chemistry of Materials, vol. 20, no. 11, pp. 3579-3586, 2008.

[5] J. Zmija and M. J. Małachowski, "Organic light emitting diodes operation and application in displays," Archives of Materials Science and Engineering, vol. 40, no. 1, pp. 5-12, 2009.

[6] V. K. Khanna, Fundamentals of Solid-State Lighting: LEDs, OLEDs, and Their Applications in Illumination and Displays, CRC Press, 2014.

[7] E. B. Namdas, A. Ruseckas, and I. D. W. Samuel, "Photophysics of fac-tris(2-phenylpyridine) iridium(III) cored electroluminescent dendrimers in solution and films," The Journal of Physical Chemistry B, vol. 108, no. 5, pp. 1570-1577, 2004.

[8] H. Klauk, Organic Electronics-Materials, Manufacturing and Applications, Wiley, 2006.

[9] Y. P. Jeon, D. C. Choo, and T. W. Kim, "Color tunable white organic light-emitting devices with a hybrid 2-methyl-9,10di(2-naphthyl)anthracene small molecule/poly(2-methoxy5-(2-ethyhexoxy)-1,4-phenylenevinylene) polymer emitting layer," Thin Solid Films, vol. 521, pp. 189-192, 2012.

[10] Z. Shen, P. E. Burrows, V. Bulović, S. R. Forrest, and M. E. Thompson, "Three-color, tunable, organic light-emitting devices," Science, vol. 276, no. 5321, pp. 2009-2011, 1997.

[11] P. E. Burrows, V. Bulovic, S. R. Forrest, L. S. Sapochak, D. M. McCarty, and M. E. Thompson, "Reliability and degradation of organic light emitting devices," Applied Physics Letters, vol. 65, no. 23, pp. 2922-2924, 1994.

[12] A. Kumar, R. Srivastava, S. S. Bawa et al., "White organic light emitting diodes based on DCM dye sandwiched in 2-methyl8-hydroxyquinolinolatolithium," Journal of Luminescence, vol. 130, no. 8, pp. 1516-1520, 2010.

[13] K. Singh, A. Kumar, R. Srivastava, P. S. Kadyan, M. N. Kamalasanan, and I. Singh, "Synthesis and characterization of 5,7-dimethyl-8-hydroxyquinoline and 2-(2-pyridyl)benzimidazole complexes of zinc(II) for optoelectronic application," Optical Materials, vol. 34, no. 1, pp. 221-227, 2011.

[14] Y. Hamada, T. Sano, M. Fujita, T. Fujii, Y. Nishio, and K. Shibata, "High luminance in organic electroluminescent devices with Bis(10-hydroxybenzo(h)quinolinato) beryllium as an emitter," Chemistry Letters, vol. 22, no. 5, pp. 905-906, 1993.

[15] Y. Li, Y. Liu, W. Bu, D. Lu, Y. Wu, and Y. Wang, "Hydroxyphenylpyridine beryllium complex $\left(\mathrm{Bepp}_{2}\right)$ as a blue electroluminescent material," Chemistry of Materials, vol. 12, no. 9, pp. 2672$2675,2000$.

[16] T. Peng, G. Li, Y. Liu et al., "Highly efficient phosphorescent organic light-emitting diodes using a beryllium metal-chelate complex as electron-transporting host material," Organic Electronics, vol. 12, no. 11, pp. 1783-1787, 2011.

[17] Y.-P. Tong, S.-L. Zheng, and X.-M. Chen, "Syntheses, structures, photoluminescence, and theoretical studies of a class of beryllium(II) compounds of aromatic N,O-chelate ligands," Inorganic Chemistry, vol. 44, no. 12, pp. 4270-4275, 2005. 
[18] L. S. Hung and C. H. Chen, "Recent progress of molecular organic electroluminescent materials and devices," Materials Science and Engineering R: Reports, vol. 39, no. 5-6, pp. 143-222, 2002.

[19] T. A. Hopkins, K. Meerholz, S. Shaheen et al., "Substituted aluminum and zinc quinolates with blue-shifted absorbance/ luminescence bands: synthesis and spectroscopic, photoluminescence, and electroluminescence characterization," Chemistry of Materials, vol. 8, no. 2, pp. 344-351, 1996.

[20] A. Sharma, D. Singh, P. S. Kadyan et al., "Electroluminescent characteristics of bis(5-chloro-8-hydroxyquinolinato)-zinc(II) complex," Indian Journal of Chemistry-Section A: Inorganic, Physical, Theoretical and Analytical Chemistry, vol. 49, no. 4, pp. 448-451, 2010.

[21] A. Sharma, D. Singh, J. K. Makrandi, M. N. Kamalasanan, R. Shrivastva, and I. Singh, "Electroluminescent characteristics of OLEDs fabricated with bis(5,7-dichloro-8-hydroxyquinolinato)zinc(II) as light emitting material," Materials Letters, vol. 61, no. 23-24, pp. 4614-4617, 2007.

[22] W. Kohn, A. D. Becke, and R. G. Parr, "Density functional theory of electronic structure," The Journal of Physical Chemistry, vol. 100, no. 31, pp. 12974-12980, 1996.

[23] L. S. Sapochak, A. Padmaperuma, N. Washton et al., "Effects of systematic methyl substitution of metal (III) tris( $n$-methyl8-quinolinolato) chelates on material properties for optimum electroluminescence device performance," Journal of the American Chemical Society, vol. 123, no. 26, pp. 6300-6307, 2001. 

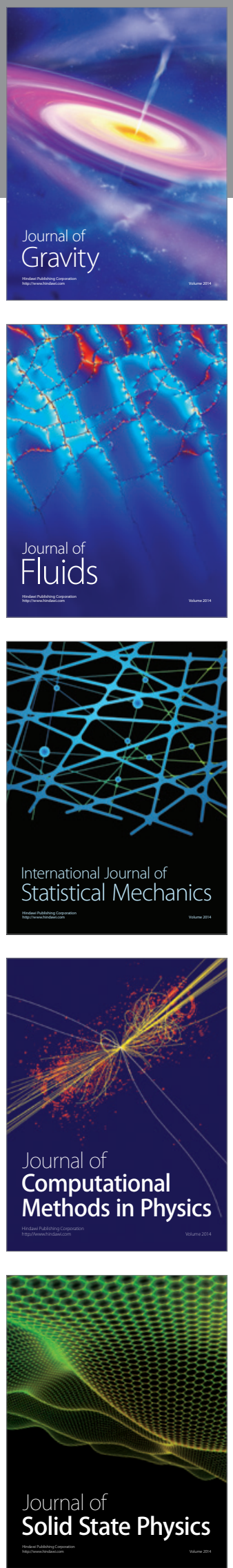

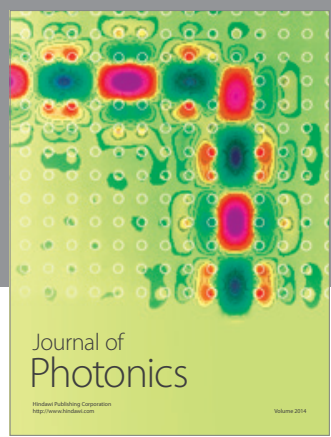

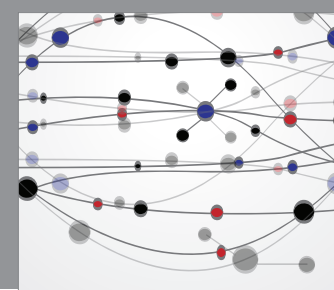

The Scientific World Journal

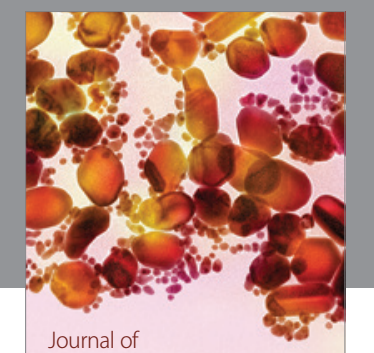

Soft Matter
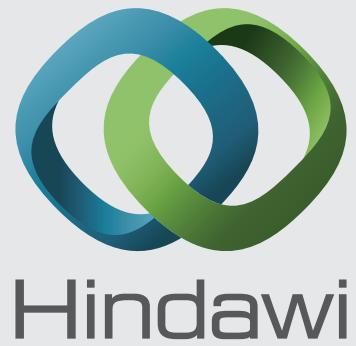

Submit your manuscripts at

http://www.hindawi.com
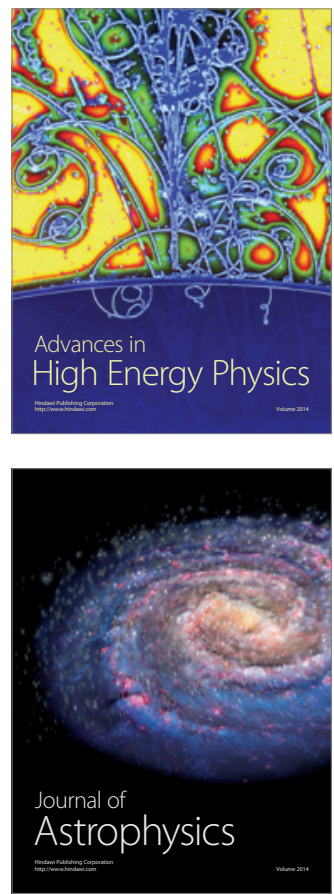
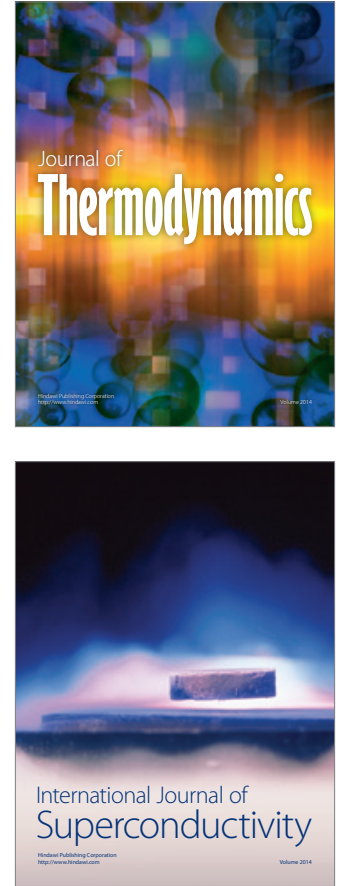
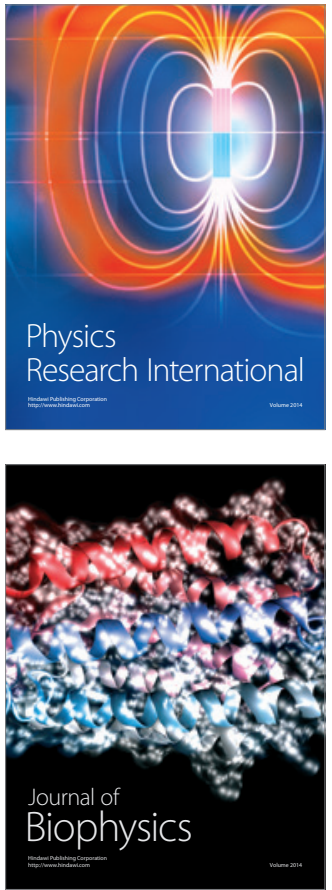
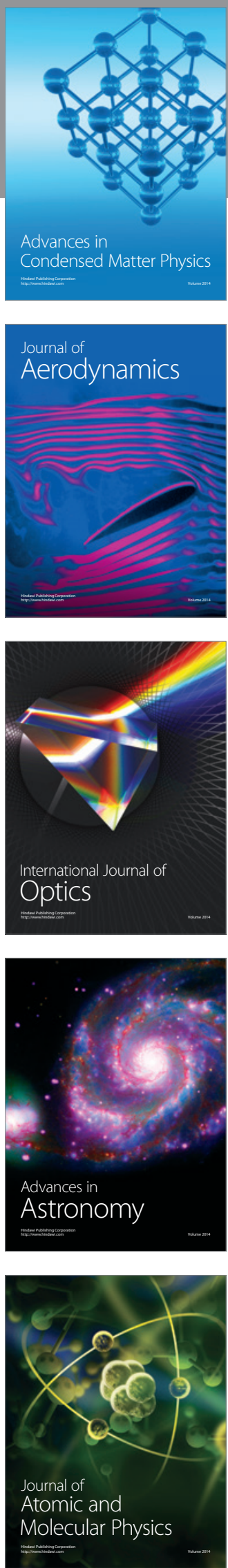